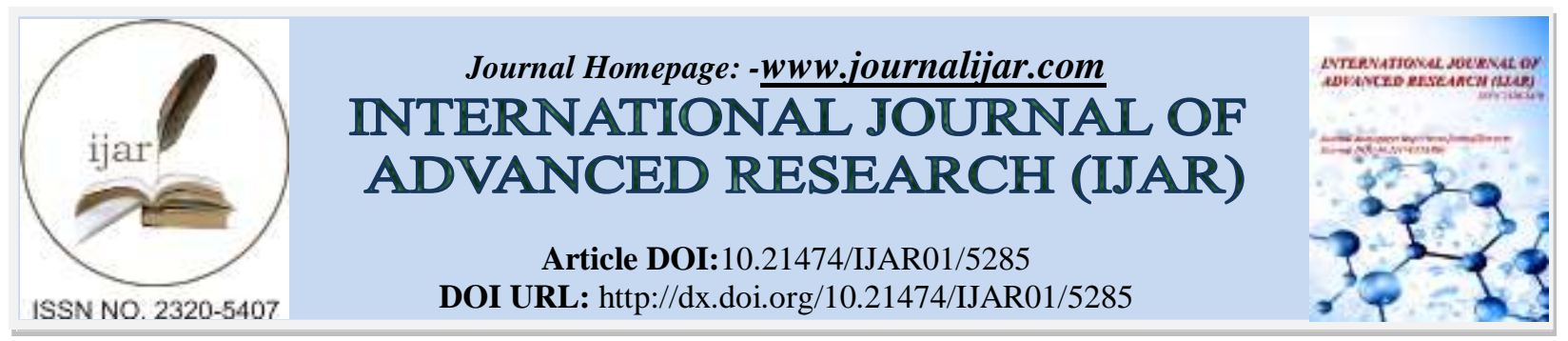

RESEARCH ARTICLE

\title{
DGS LOADED DUAL BAND MM-WAVE ANTENNA FOR 5G COMMUNICATIONS.
}

\author{
Anish Sood and Vijay Kumar. \\ School of Electronics Engineering VIT University, Vellore.
}

\section{Manuscript Info}

Manuscript History

Received: 26 June 2017

Final Accepted: 28 July 2017

Published: August 2017

\begin{abstract}
In this paper, a dual band slotted microstrip patch antenna for $5 \mathrm{G}$ communication has been presented. Excitation is provided by a singlefeed microstrip line which compensates for link loss and is desirable for high gain antenna implementations. Inset feed has also been used in the feed to offer a degree of freedom which enables efficient single carrier transmission. Defected ground structures (DGS) have been introduced in order to enhance the performance. The positions and dimensions of L-shaped slots significantly affect the antenna performance parameters. $10 \mathrm{~dB}$ impedance matching bandwidth of about $1 \mathrm{GHz}$ and $1.2 \mathrm{GHz}$ at central frequencies $28 \mathrm{GHz}$ and $38 \mathrm{GHz}$ with a gain of $7.8 \mathrm{dBi}$ and $8.2 \mathrm{dBi}$ has been obtained respectively.
\end{abstract}

Copy Right, IJAR, 2017,. All rights reserved.

\section{Introduction:-}

The rapid increase of smartphone users and various new features of smartphones have created a demand for high quality wireless communication systems. Cellular providers are limited to a carrier frequency spectrum of $700 \mathrm{MHz}$ to $2.6 \mathrm{GHz}$ [1].According to the International Telecommunication union (ITU) there has been exponential increase in mobile cellular subscriptions with over 7 billion subscriptions, exceeding the world's population, this has led to a global shortage of spectrum and has persuaded the exploration of underutilized mmwave frequency spectrum for 5G communication [2]. Frequency band of $28 \mathrm{GHz}$ and $38 \mathrm{GHz}$ is considered to be promising for $5 \mathrm{G}$ communication. Future 5G wireless communication systems must satisfy three requirements i) a high throughput ii) less energy consumption iii) ability to simultaneously serve multiple users.[3-6]

DGS is realized by carving off a simple shape from the ground plane. A defected ground antenna can be designed for a wide range of frequencies to transmit and receive. DGS disturbs the shielded current distribution which results in a controlled excitation and propagation of electromagnetic waves through the substrate layer[7-8]. Variation in the inset length does not produce any change in resonant frequency but a variation in inset width changes the resonant frequency.[9]

In this paper, a simple microstrip patch antenna based on two nested patches has been selected; DGS has been etched into the ground plane. The designed antenna has be analyzed by means of commercial simulation software HFSS. Fabrication of the prototype has been done on an RT/duroid 5880 substrate and its performance has been experimentally verified using vector network analyzer. 


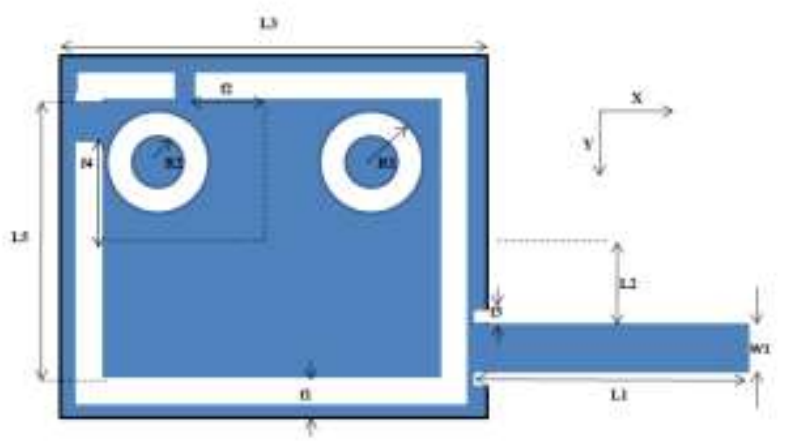

Fig.1:-Geometrical parameters of the antenna.

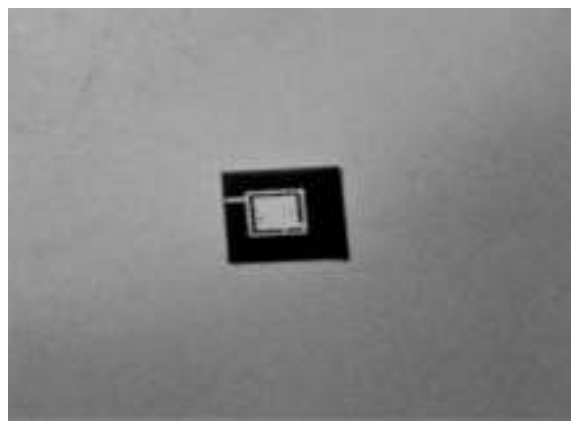

Fig.2:-Prototype of antenna.

\section{Antenna design:-}

The designed prototype is a square microstrip patch antenna consisting of two nested patches with a defected ground. The antenna is designed on an RT/duroid 5880 substrate with dielectric constant 2.2, loss tangent 0.0009 and a height of $0.508 \mathrm{~mm}$. A square patch of dimensions $3.1 \mathrm{~mm} \times 3.1 \mathrm{~mm}$ is fabricated upon the substrate material and two symmetrical ring shaped metal have been completely stripped from the ground plane of the antenna. The antenna is fed by a single feed microstrip line and is located $0.9 \mathrm{~mm}$ below the center of the square patch, the microstrip line is $1.5 \mathrm{~mm}$ long and has a width of $0.3 \mathrm{~mm}$. Inset feed with a width of $0.1 \mathrm{~mm}$ and length of $0.15 \mathrm{~mm}$ is used at the feed which provides a degree of freedom and enables efficient single carrier transmission. L-shaped slots which are near the patch edge creates capacitive and inductive effects which has resulted in operation at two resonant frequencies. Changing the length of the L-shaped slots causes a shift in the center frequencies of both the upper and the lower bands. Slot width is kept constant as simulations show that frequency Ratio changed and the gap was widened.

Table I:-Design Parameters Of The Proposed Antenna (UNIT: mm).

\begin{tabular}{|l|l|l|l|l|}
\hline f1 & R1 & R2 & Wf & L1 \\
\hline 0.2 & 0.44 & 0.22 & 0.3 & 1.65 \\
\hline L2 & f2 & f4 & L3 & L5 \\
\hline 0.9 & 1 & 0.1 & 3.1 & 2.3 \\
\hline
\end{tabular}

\section{Design Methodology:-}

Design of the antenna was done by using conventional methods. The fields undergo fringing effects because the length and the width of the patch have finite dimensions. Since $\frac{\mathrm{L}}{h} \gg 1$ the effects of fringing are reduced it is essential to know that fringing effects the resonant frequency of the antenna.

Most of the electric field lines reside in the substrate owing to the reason that $\frac{\mathrm{W}}{\mathrm{h}}>>1$ and $\varepsilon_{r}>1$.the electric field lines concentrate mostly in the substrate. 
Another term known as effective dielectric constant $\varepsilon_{r e f f}$ has been introduced due to fringing effects.

The effective dielectric constant can be in the range $1<\varepsilon_{r e f f}<\varepsilon_{r}$, for designing the antenna we should specify the dielectric constant $\left(\varepsilon_{r}\right)$, the resonant frequency $\left(f_{r}\right)$, and the height of the substrate $\mathrm{h}$.

First step done was to determine a practical width which would help in giving good radiation efficiencies

$$
W=\frac{C}{2 f_{r} \sqrt{\frac{\left(E_{r}+1\right)}{2}}}
$$

Next step was that was done was to determine the effective dielectric constant of the antenna using the formula

$$
\varepsilon_{\text {reff }}=\frac{\left(\varepsilon_{\mathrm{r}}+1\right)}{2}+\frac{\left(\varepsilon_{\mathrm{r}}-1\right)}{2}\left[1+12 \frac{\mathrm{h}}{\mathrm{W}}\right]^{-\frac{1}{2}}
$$

Then we determined the extension of the length $\Delta \mathrm{L}$ using

$$
\frac{\Delta \mathrm{L}}{\square}=0.412 \frac{\left(\varepsilon_{\text {reff }}+0.3\right)\left(\frac{\mathrm{w}}{\mathrm{h}}+0.264\right)}{\left(\varepsilon_{\text {reff }}-0.258\right)\left(\frac{\mathrm{w}}{\mathrm{h}}+0.8\right)}
$$

The actual length of the patch $\mathrm{L}$ was found using the formula

$$
\mathrm{L}=\frac{\mathrm{c}}{2 \mathrm{f}_{0} \sqrt{\varepsilon_{\text {reff }}}}-2 \Delta \mathrm{L}
$$

Finally we determined the resonant frequency for the dominant $\mathrm{TM}_{010}$ mode as a function of length using the formula [10]

$$
\left(f_{\mathrm{r}}\right)_{010}=\frac{1}{2 \mathrm{~L}_{\text {eff }} \sqrt{\varepsilon_{\text {reff }}} \sqrt{\varepsilon_{0} \mu_{0}}}
$$

\section{Results And Discussion:-}

The impedance bandwidths are $1 \mathrm{GHz}$ at $28 \mathrm{GHz}$ band with a return loss of $-22 \mathrm{db}$ and $1.2 \mathrm{GHz}$ at $38 \mathrm{GHz}$ band with a return loss of 36db.fig. shows the radiation pattern at $\Phi=0^{\circ}$ for $28 \mathrm{GHz}$ and $38 \mathrm{GHz}$.fig. shows radiation pattern at $\Phi=90^{\circ}$ for the two frequency bands. The gain obtained is $7.8 \mathrm{db}$ at $28 \mathrm{GHz}$ and $8.2 \mathrm{db}$ at $38 \mathrm{GHz}$.

From the above simulated and experimental results it can be concluded that the introduction of defect in the ground plane has led to an increase in impedance bandwidth. The radiation properties of the antenna have also improved with the introduction of DGS as compared to the structure without it.

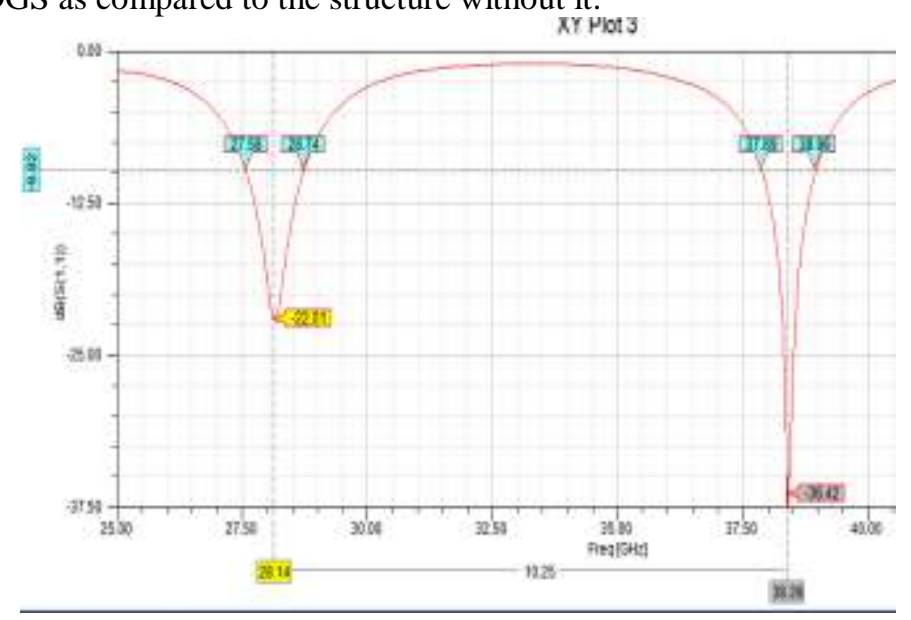

Fig.3:-Reflection coefficient of the antenna 


\section{Conclusion:-}

A novel defected ground square microstrip patch antenna is presented and tested. It has been observed that using the defected ground geometry and optimizing antenna parameter results in good impedance matching with high impedance bandwidth. The designed antenna shows dual band operation and operates in the Ka-band in the frequency range $28-38 \mathrm{GHz}$ it is also observed that a good antenna gain is obtained by introducing the defected ground plane. The antenna can be used for wideband applications due to the enhanced bandwidth. The proposed antenna is applicable for various wideband communication systems especially working in the Ka-band.

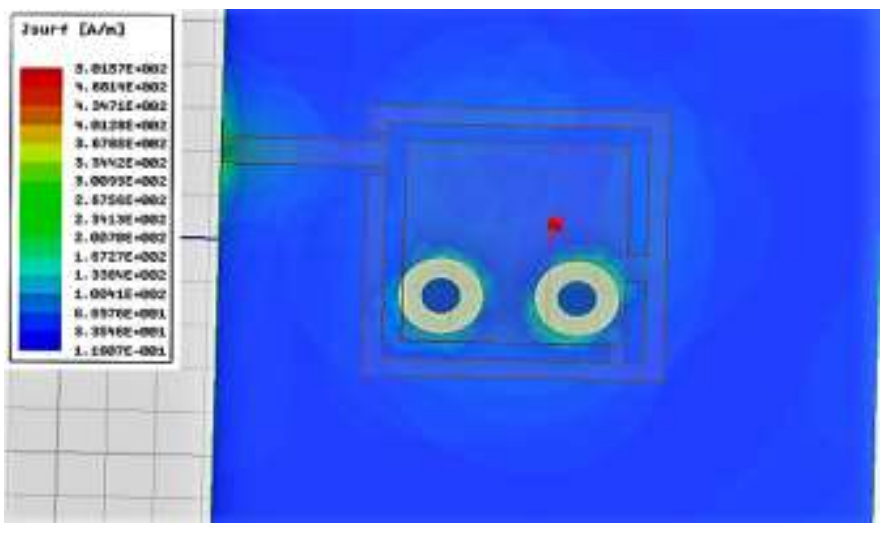

(a)

(b)

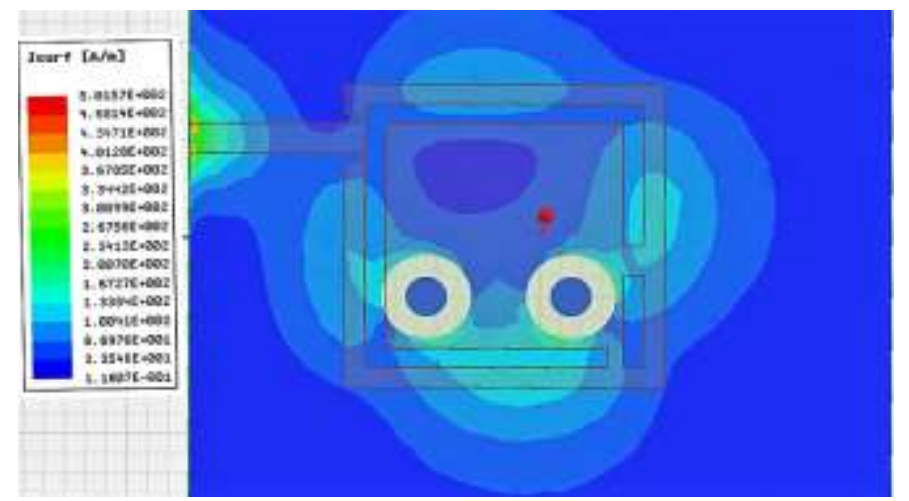

Fig.4:-Current distribution at ground plane at (a) $28 \mathrm{GHz}$ and (b) $38 \mathrm{GHz}$
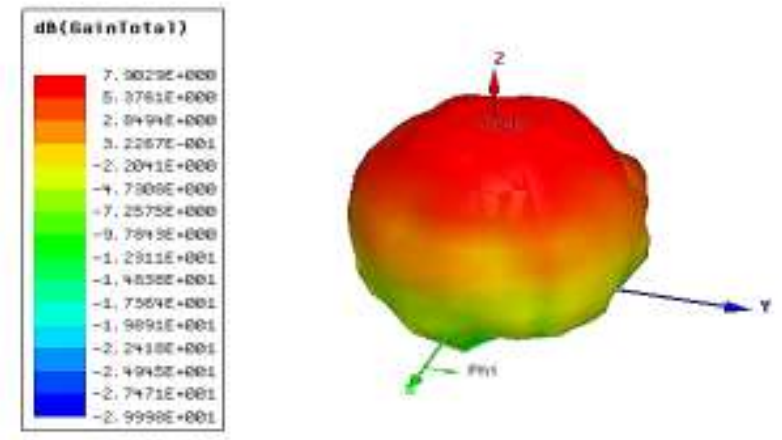

(a) 

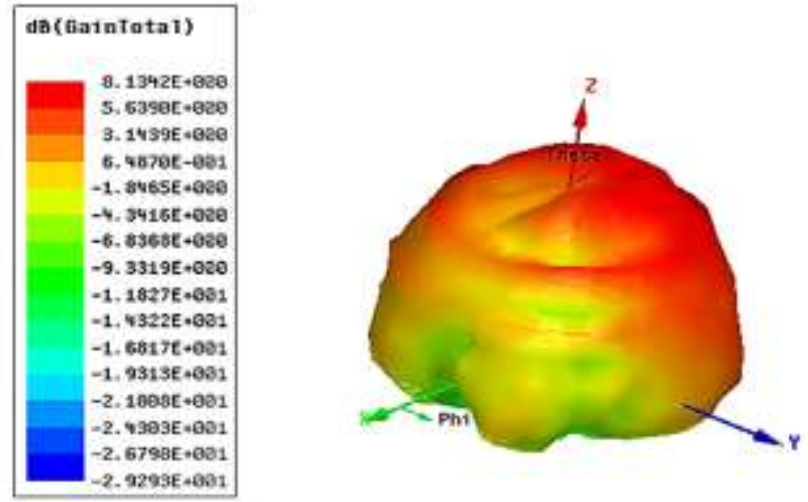

(b)

Fig.5:-Gain of the antenna at (a) $28 \mathrm{GHz}$ and (b) $38 \mathrm{GHz}$

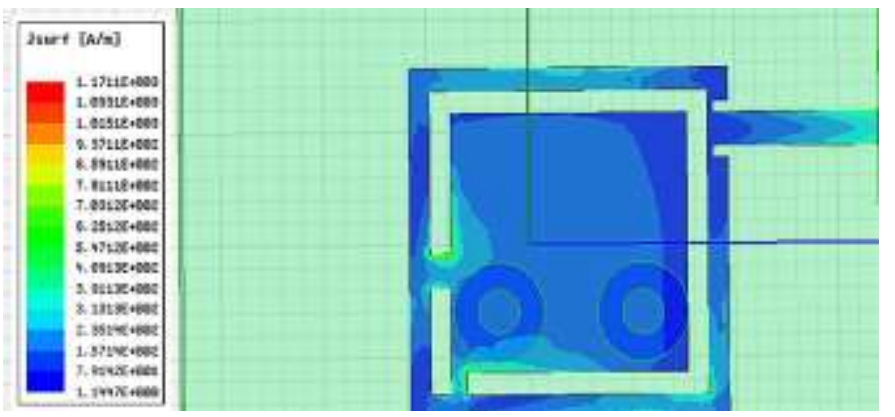

(a)

(b)

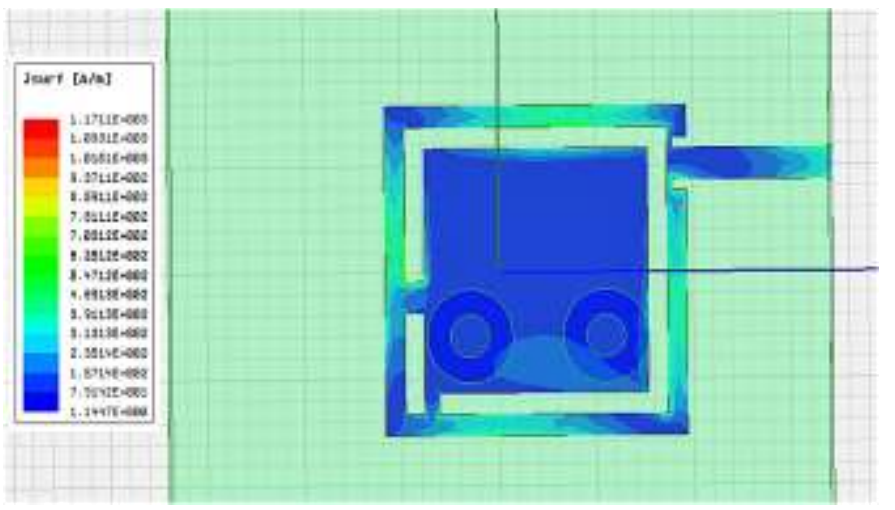

Fig.6:-current distributions of patch at (a) $28 \mathrm{GHz}$ and (b) $38 \mathrm{GHz}$

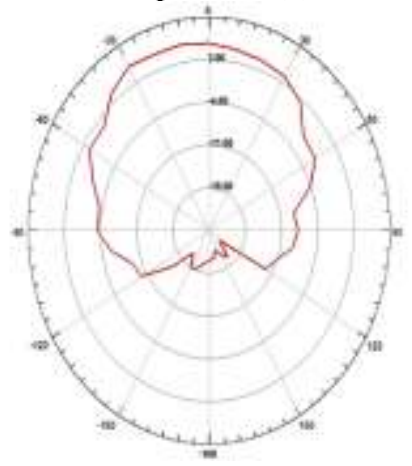

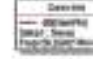


(a)

(b)
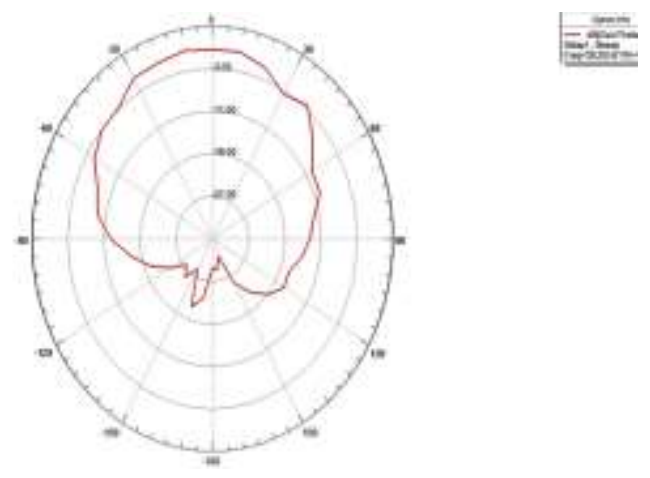

Ig.7:-Radiation pattern of antenna at $28 \mathrm{GHz}$ when (a) $\Phi=0^{\circ}$ (b) $\Phi=90^{\circ}$
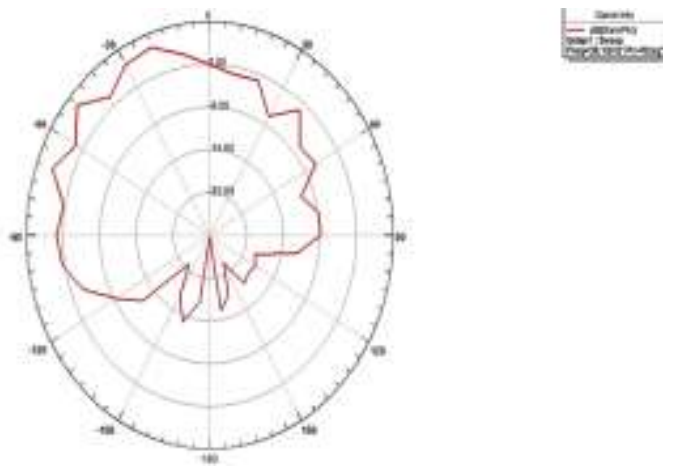

(a)

(b)
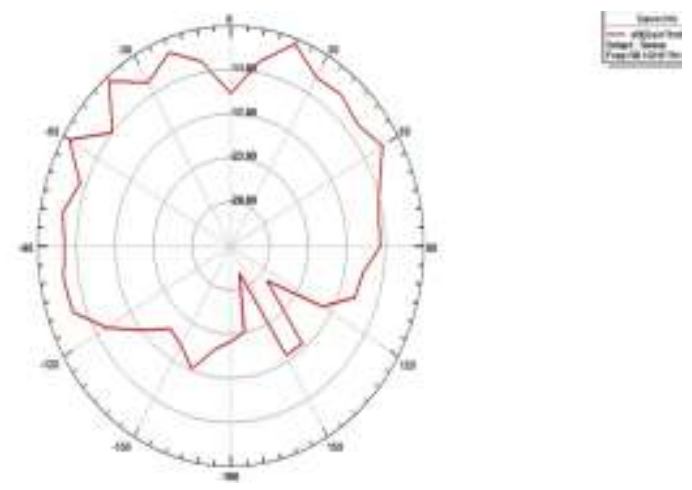

\section{Acknowledgement:-}

Fig.7:-Radiation pattern of antenna at $28 \mathrm{GHz}$ when $(\mathrm{a}) \Phi=0^{\circ}$ (b) $\Phi=90^{\circ}$

I would also like to thank VIT University for providing me the facilities and also such a wonderful opportunity, last but not the least I would like to thank my parents and friends who helped me a lot in finalizing this project within the limited time frame.

\section{References:-}

1. T. Rappaport, et al. "Millimeter wave mobile communications for 5G cellular: It will work!." IEEE Access, vol. 1, pp. 335-349, 2013.

2. ICT Data and Statistics Division " ICT Facts \& Figures the world in 2015" Telecommunication Development Bureau International Telecommunication Union Place des Nations Geneva, May 2015.

3. Rupendra Nath Mitra,Dharma P. Agrawal, "5G mobile technology: a survey " ICT Express 1(2015) pp. 132137. 
4. Low Ching Yu and Muhammad Ramlee Kamarudin "Investigation of patch phase array antenna orientation at 28GHz for 5G applications" Procedia computer science 86 (2016), pp. 47-50.

5. Guntis Ancansa,, Vjaceslavs Bobrovsa, Arnis Ancans, Diana Kalibatienec. " Spectrum Considerations for 5G Mobile Communication Systems." ICTE 2016, December 2016, Riga, Latvia Procedia Computer Science 104 ( 2017 ) pp. $509-516$

6. [7] Ian F. Akyildiz, Shuai Nie, Shih-Chun Lin, Manoj Chandrasekaran, "5G Roadmap: 10 Key Enabling Technologies", Computer Networks (2016)

7. L. H. Weng, Y. C. Guo, X. W. Shi, and X. Q. Chen" an overview on defected ground structure" Progress In Electromagnetics Research B, Vol. 7, (2008), pp. 173-189,.

8. S. H. Zainud-Deen, M. E. Badr, E. El-Deen, K. H. Awadalla and H. A. Sharshar "Microstrip Antenna With Defected Ground Plane Structure as a sensor for landmines detection” Progress In Electromagnetics Research B, Vol. 4, 27-39, 2008

9. D. M. Pozar "Microstrip Antennas" Invited Paper proceedings of the IEEE, vol. 80, no. 1, january 1992

10. Constantine A. Balanis " Microstrip Antennas" in Antenna Theory analysis and design, $3^{\text {rd }}$ ed. New Jersey. 